\title{
Investigation of infrared assisted dryer effect on energy consumption during drying of tomato
}

\author{
Hany S. EL-Mesery ${ }^{1,2}$, Hanping Mao ${ }^{1, *}$ \\ ${ }^{1}$ Key Laboratory of Modern Agriculture Equipment and Technology, School of Chemistry and Chemical Engineering, Jiangsu \\ University, Zhenjiang 212013, China \\ ${ }^{2}$ Department of Crop Handling and Processing, Agricultural Engineering Research Institute, Agricultural Research Center, 12311, \\ Giza, Egypt
}

\section{A R T I C L E IN F O}

\section{Article history:}

Received 1 February 2017

Received in revised form

25 September 2017

Accepted 11 October 2017

\section{Keywords:}

Energy

Infrared radiation

Combined infrared and hot air

Tomato slices

\begin{abstract}
A B S T R A C T
The specific energy consumption involved in the two drying processes was estimated from the energy supplied to the various components of the dryer during the drying period. The specific energy consumption was computed by dividing the total energy supplied by amount of water removed during the drying process. Tomato slices were dried from an initial moisture content of 15.9 to 0.17 gwater/gdry solids by involving infrared radiation and convection-infrared combination drying, respectively. Specific energy consumption for the tomato slices were compared at these different drying conditions. In particular, the experiments were carried out at three different infrared intensity levels $0.15,0.2$ and $0.3 \mathrm{~W} / \mathrm{cm}^{2}$ and air velocity levels 0.5 , 0.7 and $1 \mathrm{~m} / \mathrm{s}$ under infrared drying. For combination of infrared and hot-air convection drying there were three air temperature levels of 40,50 and $60^{\circ} \mathrm{C}$ and three air velocity levels $0.5,0.7$ and $1 \mathrm{~m} / \mathrm{s}$ while the infrared intensity was set at $0.15,0.2$ and $0.3 \mathrm{~W} / \mathrm{cm}^{2}$. Results of data analysis showed that the lowest and highest energy consumption levels in drying tomato slices were associated with the hot air convection-infrared combination and infrared dryers, respectively. In infrared drying, it was observed that increasing the air velocity increases the drying time and consequently the amount of energy consumed. However, a reduction in energy consumption was noted with increasing infrared intensities under combination drying relative to infrared drying alone.
\end{abstract}

(C) 2017 The Authors. Published by IASE. This is an open access article under the CC BY-NC-ND license (http://creativecommons.org/licenses/by-nc-nd/4.0/).

\section{Introduction}

Tomato (Lycopersicon esculentum Mill) is the world's most commonly commercially produced vegetable. It is grown worldwide on a variety of soils due to climatic conditions. The world tomato production reached 159023383 metric tons, and Turkey produced about 11003400 metric tons of tomatoes in the 2011. China, India, United States, Turkey and Egypt are the leading tomato-growing countries. Tomato is a rich source of minerals, vitamins, organic acid and dietary fibre (Rajkumar et al., 2007). It is used to great extent in the fresh state and in some processes as juice, puree and sauces, canned and dried (Akanbi et al., 2006). Fresh tomatoes can be dried in different shapes such as

\footnotetext{
* Corresponding Author.

Email Address: maohp@ujs.edu.cn (H. Mao)

https://doi.org/10.21833/ijaas.2017.012.014

2313-626X/C 2017 The Authors. Published by IASE.

This is an open access article under the CC BY-NC-ND license

(http://creativecommons.org/licenses/by-nc-nd/4.0/)
}

halves, slices and quarters and powders and used as a component for pizza and various vegetable and spicy dishes (Khazaei et al., 2008).

Drying is one of the most common methods used for apricot processing. It extends their shelf life by reducing the moisture content to a low level at which microbial spoilage is avoided (Dai et al., 2015). Convective drying is one of the oldest and alternative drying methods but may deteriorate the quality of the final product. The high temperatures and long drying times in the drying method often causes heat damage and adversely affects the quality criterions such as colour, flavour, texture and nutritional value of dried products (Adiletta et al., 2015). Therefore, it is needed to develop new drying systems and design new dryers.

Water loss from foods is a very energy-intensive process. Energy and time efficiency is one of the most significant design and operation parameters in food processing (Mongpraneet et al., 2002; Sharma et al., 2005). Low thermal conductivity and casehardening of materials are the main factors 
responsible for slowing down convective drying. Infrared heating offers many advantages over conventional drying under similar conditions. Comparative studies for infrared drying versus other techniques have shown that infrared radiation is faster than convection (Nowak and Lewicki, 2005). Infrared radiation energy is transferred from the heating element to the product, heating the material more rapidly and uniformly without heating the surrounding air (Heybeli and Ertekin, 2011). The irradiated surface evaporates much more water and drying time is shortened by up to half (Nowak and Lewicki, 2004). Infrared radiation has been applied in conjunction with several drying processes because of these advantages (Das et al., 2009). Combined with hot air convection drying, infrared heating can save $20 \%$ of drying time compared with the infrared drying alone (Sun et al., 2007). Convective air and far infrared radiation have been used for drying fruits to produce fat-free snacks (Hebber et al., 2004). The depth of radiation penetration, however, depends on the characteristics of the material and wavelength of radiation. In this article, we report a detailed analysis to optimize convective infrared drying of tomato slices to obtain energy consumption.

\section{Materials and methods}

\subsection{Material}

The fresh tomato slices (Lycopersicon esculentum) were used in the present study. They were procured in bulk from the local market and then stored in a refrigerator that was maintained at $4 \mathrm{oC}$ and $60 \%$ relative humidity. The tomatoes were cut into slices of approximately $5 \pm 0.1 \mathrm{~mm}$ thickness with a sharp stainless steel knife. Three measurements were made on each slice for its thickness, using a vernier caliper and the corresponding average values were considered and those siles that did not need the requirements removed.).

\subsection{Drying equipment}

The infrared radiation dryer (IR) is comprised of two components i.e. a drying chamber having a tube type infrared heater and a fan. The infraredconvection dryer comprised (IR-HA) of three components, a drying chamber having a tube type infrared emitters and hot air supply unite. The air velocity was regulated with the help of an air control valve placed in the air supply line to the drying chamber.

Air was forced through the dryers using an axial flow blower and the velocity of air was controlled by use of an air control valve in all dryers. The air velocity inside the drying chamber was measured at a position just above the conveyor-belt surface using a hot wire anemometer (Testo, 405 V1). Air was heated as it passed through two spiral type electrical heaters that had a heating capacity of $1.5 \mathrm{~kW}$ each.
The air temperature was measured using T-type thermocouples (Testo 925) connected to a data logger measuring to an accuracy of $\pm 1^{\circ} \mathrm{C}$.

\subsection{Drying methods}

The initial moisture content of fresh tomato was measured by drying a $20 \mathrm{~g}$ sample in an oven set at $105{ }^{\circ} \mathrm{C}$ for 24 hours and was expressed in g water/g dry matter (Helrick, 1990). The initial moisture content of the tomato sample varied between 18.5 and $15.99 \mathrm{~g}$ water/g dry matter.

Infrared radiation drying: Factors investigated in infrared drying were infrared radiation intensity $0.15,0.2$ and $0.3 \mathrm{~W} / \mathrm{cm}^{2}$ and three air velocities of $0.5,0.7$ and $1.0 \mathrm{~m} / \mathrm{s}$ were applied at $25 \pm 1^{\circ} \mathrm{C}$, ambient air temperature (no heat).

Combination of infrared and hot-air convection drying: The experiments were performed in a combined infrared and hot air convection dryer at three levels of radiation intensity $0.15,0.2$ and 0.3 $\mathrm{W} / \mathrm{cm}^{2}$ and three air temperature levels of 40,50 and $60{ }^{\circ} \mathrm{C}$ at three air velocity levels $0.5,0.7$ and 1 $\mathrm{m} / \mathrm{s}$. Drying runs at each experimental setting of infrared intensity, air temperature and air flow velocity were repeated three time and the average values recorded.

After dryer preparation and its adjustment for desired conditions according to the experimental plan, a $100 \mathrm{~g}$ mass of tomato slices was placed in the drying chamber in a single layer. Every 15 minutes throughout the drying period the mass of the drying tomato was measured using a digital electronic balance (METTLER PM30, Germany) having an accuracy of $\pm 0.01 \mathrm{~g}$. The drying was continued until the moisture content of tomato slices was reduced to approximately $0.17 \mathrm{~g}$ water/g dry mater.

\subsection{Specific energy consumption}

The total energy consumption was defined as the sum of the electrical energy consumed during drying process and included the energy used to drive the fan, and energy for heating the air. In the infrared dryer, used energy consumption is the sum of energy consumed by the infrared heater and the ventilator fan used in moving the air. The amount of energy consumed in the combined infrared and hot air convection dryer is obtained from the sum of the energies used to heat the air, drive the fan and in the infrared heater. This energy was measured using a digital electric counter (Kaan, type 101) with 0.01 kWh precision.

The specific energy consumption was estimated, in all of the different drying methods considering the total energy supplied to dry tomato slices from and the amount of water removed over entire drying period initial moisture content of about $15.30 \mathrm{~kg}$ water/kg dry matter to a desired moisture content of approximately $0.17 \mathrm{~kg}$ water $/ \mathrm{kg}$ dry matter. The specific energy consumption (SEC) of tomato slices during drying at different drying methods was expressed in $\mathrm{MJ} / \mathrm{kg}$ of water evaporated, and 
calculated according to Eq. 1 (EL-Mesery and Mwithiga, 2012):

$\mathrm{SEC}=\frac{\text { Total energy supplied in drying process, } \mathrm{MJ}}{\text { Amount of water removed during drying,kg }}$

\section{Results and discussion}

\subsection{Infrared radiation drying (IR)}

Fig. 1 shows the specific energy consumption (SEC) at infrared radiation intensities and air velocities in the infrared dryer (IR). The lowest specific energy consumption is $8.51 \mathrm{MJ} / \mathrm{kg}$ and was obtained at a radiation intensity of $0.3 \mathrm{~W} / \mathrm{cm}^{2}$ and air velocity of $0.5 \mathrm{~m} / \mathrm{s}$. The maximum specific energy consumption was $23.83 \mathrm{MJ} / \mathrm{kg}$ obtained at 0.15 $\mathrm{W} / \mathrm{cm}^{2}$ and $1 \mathrm{~m} / \mathrm{s}$. A reduction in (SEC) was observed with the increase of radiation intensity and the decrease of air velocity. The increase in specific energy consumption with air velocity can be attributed to the cooling of the sample's surface by the passing air inside the drying chamber, where by increasing the air velocity, the air cooling process will also increase. Also, with increasing infrared intensity, due to the increase in sample temperature and evaporation rate and the decrease in drying time, the specific energy for drying of tomato slices decreases (Das et al. 2004; Ruiz Celma et al., 2009).

Using multiple regression analysis, a relationship was established between specific energy consumption, intensity of infrared radiation and air velocity. The relevant equations and coefficient of determination are present in Eq. 2.

SEC $=27.6-151.4 \mathrm{~V}+0.64 \mathrm{IR}+290.6 \mathrm{~V}^{2}+$ 12.4 IR2-26.8 V. IR $R^{2}=0.996$

In the above equation, IR is the intensity of infrared radiation $\left(\mathrm{W} / \mathrm{cm}^{2}\right)$ and $\mathrm{V}$ is air velocity (m/s).

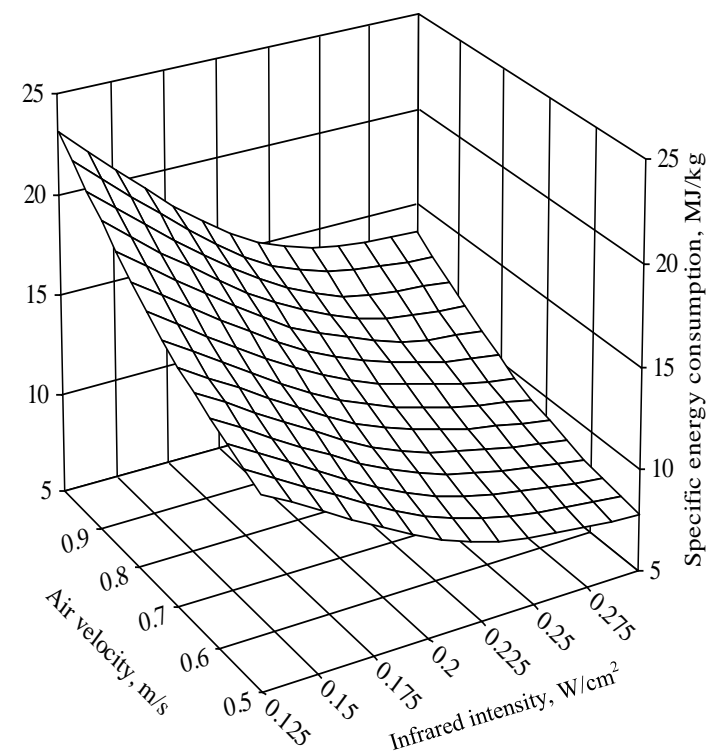

Fig. 1: Effect of infrared radiation intensity and air velocity on the specific energy consumption when drying tomato slices

\subsection{Combined infrared and hot air convection drying (IR-HA)}

Figs. 2A-2C shows the SEC for the drying of tomato slices in an (IR-HA) dryer at various air velocities. It is clear that the SEC decreases with increase in both radiation intensity and air temperature. The SEC, at a fixed air velocity of 0.5 $\mathrm{m} / \mathrm{s}$, decreased with increasing infrared radiation intensity. This was also true for the other air velocity levels $(0.7$ and $1 \mathrm{~m} / \mathrm{s})$. This phenomenon is due to the increase in the intensity of radiation and the subsequent increased temperature of the tomato slices. Thus, temperature gradient of product surface layer or underlying slices is increased, and as a result, the rate of moisture evaporation increases. Therefore, the required SEC decreases. As seen from Figs. 2A-2C it can be observed that the SEC increases with increase in air velocity from 0.5 to $1 \mathrm{~m} / \mathrm{s}$. This increase in SEC due to an increase in air velocity can be associated with increased cooling of the sample surface at higher air velocities which causes moisture evaporation to decrease, consequently increasing the drying time. Similar trends were observed in several researchers (Jaturonglumlert and Kiatsiriroat, 2010). Comparison of the SEC, at three air velocity levels, indicates that the lowest SEC occurring at $0.5 \mathrm{~m} / \mathrm{s}$ air velocity, $0.3 \mathrm{~W} / \mathrm{cm}^{2}$ infrared intensity, and $60{ }^{\circ} \mathrm{C}$ air temperature, was $6.78 \mathrm{MJ} / \mathrm{kg}$ and the highest value occurred at an air velocity of 1 $\mathrm{m} / \mathrm{s}$, radiation intensity of $0.25 \mathrm{~W} / \mathrm{cm} 2$, and air temperature $40{ }^{\circ} \mathrm{C}$ was $25.07 \mathrm{MJ} / \mathrm{kg}$. Multiple regression analysis of specific energy consumption, as a function of air temperature and intensity of the infrared radiation was performed and a relationship was obtained for each air velocity. For $0.5 \mathrm{~m} / \mathrm{s}$ air velocity Eq. 3

SEC $=19.1-14.4 \mathrm{IR}-0.11 \mathrm{~T}+8.8 \mathrm{IR}^{2}-4.1 \mathrm{~T}^{2}-0.01 \mathrm{IR} . \mathrm{T}$

$\mathrm{R}^{2}=0.998$

for $0.7 \mathrm{~m} / \mathrm{s}$ air velocity Eq. 4

$\mathrm{SEC}=23.4-39.3 \mathrm{IR}-0.03 \mathrm{~T}+11.1 \mathrm{IR}^{2}-0.003 \mathrm{~T}^{2}+0.3 \mathrm{IR} . \mathrm{T}$

$\mathrm{R}^{2}=0.994$

for $1 \mathrm{~m} / \mathrm{s}$ air velocity Eq. 5

$\mathrm{SEC}=48.6-54.2 \mathrm{IR}-0.6 \mathrm{~T}+69.15 \mathrm{IR}^{2}+$

$0.003 \mathrm{~T}^{2}-0.09$ IR. T

$\mathrm{R}^{2}=0.994$

where IR is infrared radiation intensity $\left(\mathrm{W} / \mathrm{cm}^{2}\right)$ and $\mathrm{T}$ is drying air temperature $\left({ }^{\circ} \mathrm{C}\right)$.

\section{Conclusion}

This study was conducted to evaluate specific energy consumption in various dryers including infrared drying, and combined infrared-hot air convection drying. Tests were conducted using tomato slices under various experimental conditions as follows. Results of data analysis showed that the lowest and 
highest specific energy consumption levels in drying tomato slices were associated with infrared and combined infrared and hot air convection dryer, respectively.

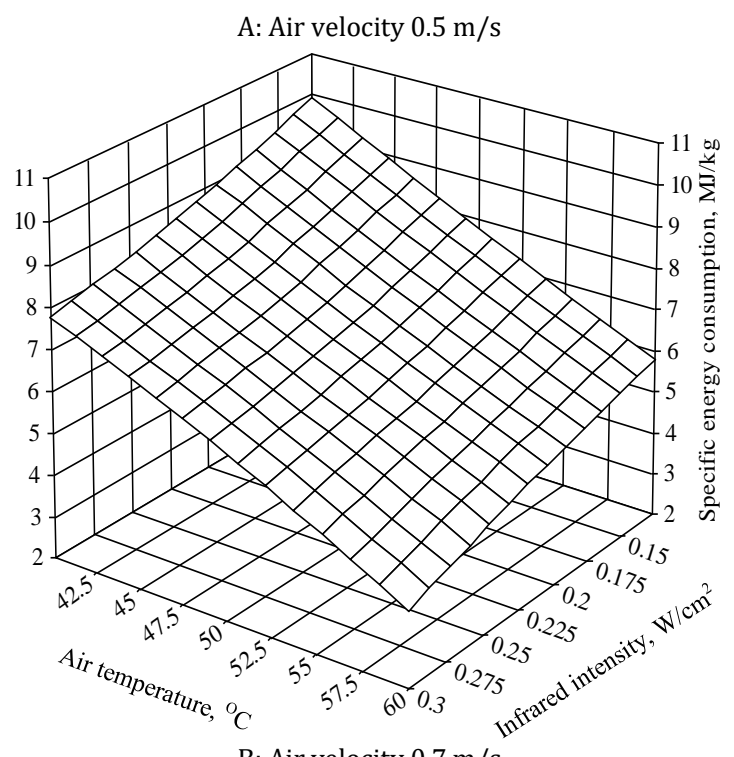

B: Air velocity $0.7 \mathrm{~m} / \mathrm{s}$

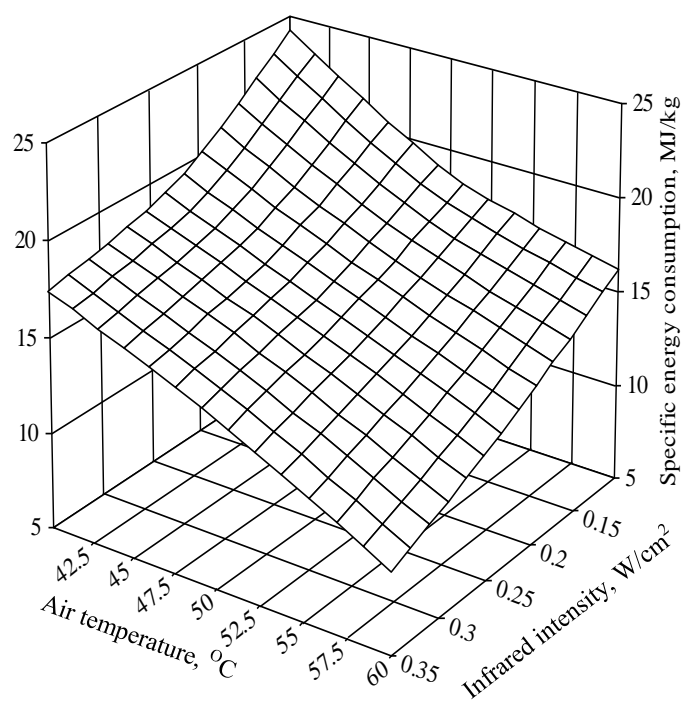

C: Air velocity $1 \mathrm{~m} / \mathrm{s}$

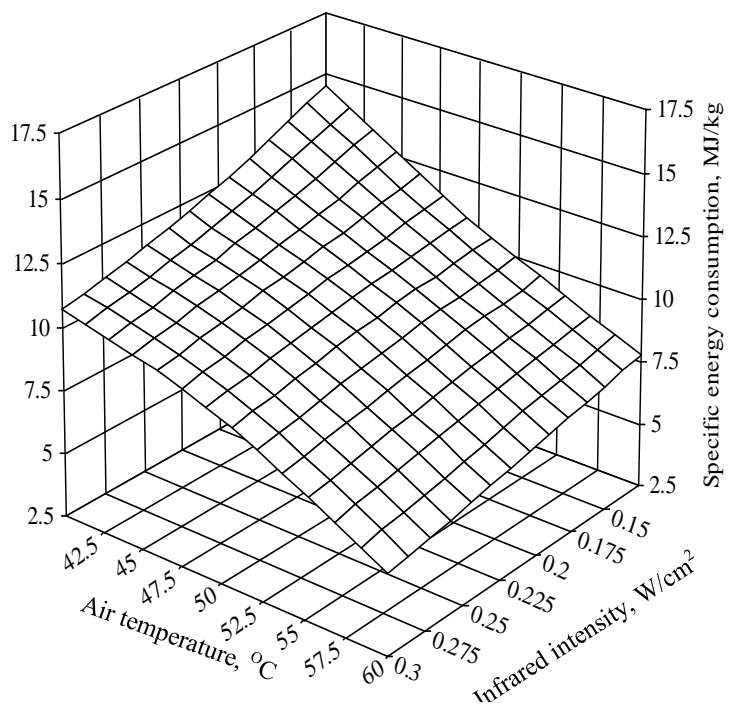

Fig. 2: The influence of infrared radiation intensity and air temperature on specific energy consumption when drying tomato slices in combined infrared and hot air convection dryer at different air velocities
In drying tomato using infrared radiation it was observed that increased air velocity increases drying time and consequently the amount of consumed energy. Conversely, specific energy consumption decreased with increasing radiation intensity. Combined infrared and hot air convection drying of tomato slices proved to have the lowest specific energy consumption.

\section{Acknowledgement}

We acknowledge that this work was supported by grants from the National Natural Science Foundation of China (No. 51475216), fund name, Damage mechanism in picking up vegetable plug seeding and multi-objective optimization of the seeding pick-up device. The Priority Academic Program Development of Jiangsu Higher Education Institutions (SFE (2014) 37), the Jiangsu Province Synergistic Innovation Center Program of Modern Agricultural Equipment and Technology (No. NZXT02201402), and the Fund for Independent Innovation of the Jiangsu Province Agricultural Science and Technology (No. CX (15)1033-5).

\section{References}

Adiletta G, Senadeera W, Liguori L, Crescitelli A, ALbanese D, and Russo P (2015). The influence of abrasive pretreatment on hot air drying of grape. Food Nutrition Sciences, 6(3): 355-364.

Akanbi CT, Adeyemi RS, and Ojo A (2006). Drying characteristics and sorption isotherm of tomato slices. Journal of Food Engineering, 73(2): 157-163.

Dai JW, Rao JQ, Wang D, Xie L, Xiao HW, Liu YH, and Gao ZJ (2015). Process-based drying temperature and humidity integration control enhances drying kinetics of apricot halves. Drying Technology, 33(3): 365-376.

Das I, Das SK, and Bal S (2004). Specific energy and quality aspects of infrared (IR) dried parboiled rice. Journal of Food Engineering, 62(1): 9-14.

Das I, Das SK, and Bal S (2009). Drying kinetics of high moisture paddy undergoing vibration-assisted infrared (IR) drying. Journal of Food Engineering, 95(1): 166-171.

EL-Mesery HS and Mwithiga G (2012). Comparison of a gas fired hot-air dryer with an electrically heated hot-air dryer in terms of drying process, energy consumption and quality of dried onion slices. African Journal of Agricultural Research, 7(31): 4440-4452.

Hebber HU, Vishwanatan KH, and Ramesh MN (2004). Development of combined infrared and hot air dryer for vegetables. Journal of Food Engineering, 65(4): 557-563.

Helrick K (1990). AOAC method 973.18-fiber (acid detergent) and lignin in animal feeds. In Official Method of Analysis of the Association of Official Analytical Chemists (Vol. 82), Association of Official Analytic Chemists, Washington, USA.

Heybeli N and Ertekin C (2011). Effects of different drying techniques on apple drying process: A Review. In the $6^{\text {th }}$ International CIGR Technical Symposium on Towards a Sustainable Food Chain-Food Process, Bioprocessing and Food Quality Management. Nantes, France.

Jaturonglumlert S and Kiatsiriroat T (2010). Heat and mass transfer in combined convective and far-infrared drying of fruit leather. Journal of Food Engineering, 100(2): 254-260.

Khazaei J, Chegini GR, and Bakhshiani M (2008). A novel alternative method for modelling the effects of air 
temperature and slice thickness on quality and drying kinetics of tomato slices: superposition technique. Drying Technology, 26(6): 759-775.

Mongpraneet S, Abe T, and Tsurusaki A (2002). Accelerated drying of welsh onion by far infrared radiation under vacuum conditions. Journal of Food Engineering, 55(2): 147-156.

Nowak D and Lewicki PP (2004). Infrared drying of apple slices. Innovative Food Science and Emerging Technologies, 5(3): 353-360.

Nowak D and Lewicki PP (2005). Quality of infrared dried apple slices. Drying Technology, 23(4): 831-846.

Rajkumar P, Kulanthaisami S, Raghavan GSV, Gariepy Y, and Orsat V (2007). Drying kinetics of tomato slices in vacuum assisted solar and open sun drying methods. Drying Technology, 25(78): $1349-1357$.

Ruiz Celma A, López-Rodríguez F, and Cuadros Blázquez F (2009). Characterisation of industrial tomato by-products from infrared drying process. Food Bioproducts Processing, 87(4): 282-291.

Sharma GP, Verma RC, and Pathare PB (2005). Thin layer infrared radiation drying of onion slice. Journal of Food Engineering, 67(3): 361-366.

Sun J, Hu X, Zhao G, Wu J, Wang Z, Chen F, and Liao X (2007). Characteristics of thin-layer infrared drying of apple pomace with and without hot air pre-drying. Revista de Agaroquimica y Tecnologia de Alimentos, 13(2): 91-97. 